\title{
Görüntüdeki Farklı Nesneyi Renk ve Şekil Özelliklerini Kullanarak Tespit Etme
}

\author{
Şafak ALTAY AÇAR ${ }^{1}$ \\ ${ }^{1}$ Karabük Üniversitesi, Yenice Meslek Yüksekokulu, Bilgisayar Teknolojileri Bölümü, Karabük, Türkiye
}

(Alınış / Received: 23.10.2020, Kabul / Accepted: 15.03.2021)

\section{Araștırma Makalesi}

\section{Anahtar Kelimeler}

Nesne tespiti,

Yarışmacı öğrenme ağı, Kümeleme

\begin{abstract}
Özet: Bu çalışmada, bir görüntü üzerindeki nesnelerden farklı olanı tespit eden iki farklı yöntem sunulmaktadır. İlk yöntemde görüntüdeki nesnelerin renk özellikleri kullanılmaktadır. İkinci yöntemde ise şekil özellikleri kullanılmaktadır. Öncelikle görüntü üzerindeki nesneler 2 girişli ve 6 çıkışlı bir yarışmacı öğrenme ağı ile kümelendirilerek belirlenmektedir. Daha sonra sunulan yöntemlerden biri kullanılarak nesnelerden farklı olan tespit edilmektedir. Deneysel çalışmalarda 80 farklı nesne ve 160 farklı görüntü kullanılmıștır. Renk özelliklerini kullanan yöntem \%90 başarı elde etmiştir. Şekil özelliklerini kullanan yöntem \%73.75 bașarı elde etmiş̧tir. Elde edilen sonuçlar birbirleriyle karşılaştırılarak değerlendirilmiştir. Ayrıca yarışmacı öğrenme ağının kümelendirme performansı da incelenmiştir. Gelecek çalışmalar hakkında öneriler sunulmuştur.
\end{abstract}

\section{Detection Different Object in Image Using Colour and Shape Properties}

\section{Keywords}

Object detection, Competitive learning network,

Clustering

\begin{abstract}
In this study, two different methods which detect different one from objects in an image are presented. In the first method, colour properties of objects in image are used. In the second method, shape properties are used. Firstly, objects in image are determined by clustering using a competitive learning network with 2 inputs and 6 outputs. Then, different one from objects is detected by using one of presented methods. 80 different objects and 160 different images are used in experimental studies. The method using the colour properties achieved 90\% success. The method using the shape properties achieved $73.75 \%$ success. Obtained results were evaluated by comparing each other. Also, clustering performance of competitive learning network was examined. Suggestions about future studies are presented.
\end{abstract}

\section{Giriş}

Bir görüntüdeki nesnelerin doğru bir şekilde tanımlanmalarına veya sınıflandırılmalarına ihtiyaç duyulan birçok alan bulunmaktadır. Bu alanlar sağlık bilimlerinden, tarımsal ve endüstriyel üretime kadar çeşitlilik göstermektedirler. Tanımlama veya sınıflandırma işleminin otomatik olarak bir yazılım tarafından yapılması hem ilgili işlemin süresinin azalmasına hem de doğruluğunun artmasına fayda sağlayacaktır. Bu amaca yönelik birçok çalışma yapılmaktadır. Chen ve diğerleri [1] nesne sınıflandırma, bölütleme ve tanıma da kullanmak için olasılıklı nesne modellerini öğrenme üzerine bir çalışma yapmışlardır. Sahbi ve diğerleri [2] nesne sınıflandırma amaçlı olarak bağlam bağımlı çekirdek şablonlar hakkında çalışmalar yapmışlardır. Chen ve diğerleri [3] görüntü işleme ve makine görme teknolojisi destekli, dairesel nesneleri saptayıp sinıflandıran bir yöntem sunmuşlardır. Kim ve diğerleri [4] endüstriyel robot uygulamaları için birçoklu nesne tanıma çalışması yapmışlardır. Çalışmalarında üç katmanlı bir perseptron ağı kullanmışlardır. Higa ve diğerleri [5] birden fazla sayıdaki nesneleri tespit etmek için nesnelerin merkez noktalarını tahmin etmeye dayalı bir yöntem önermișlerdir. Jang ve diğerleri [6] trafik video görüntüleri için nesne sinıflandıran bir çalışma sunmuşlardır. Evrişimli sinir ağı kullanmışlardır. Liang ve Juang [7] yaptıkları çalışmada hareketli 
araçları ve yayaları, statik ve zaman-mekansal özellikleri kullanarak sınıflandırmışlardır. Oka ve Morimoto [8] bir kısmı gizlenmiş nesneleri tespit edip tanıyan bir yöntem sunmuşlardır. Shehnaz ve Naveen [9] bir nesne tanıma algoritması sunmuşlardır. Çalışmalarında sınıflandırıcı olarak destek vektör makinesini kullanmışlardır. Horiguchi ve diğerleri [10] yaptıkları yüz tanıma çalışmasında çıkarılan öznitelikler arasındaki ilişkileri kullanmışlardır. Dai [11] eğitim verisi sürekli güncellenen, online video görüntülerindeki nesneleri sınıflandıran bir algoritma sunmuştur. Reddy ve Phanikrishna [12] derin öğrenme sinir ağlarını kullanarak bir nesne tanıma çalışması yapmışlardır. Zhang ve diğerleri [13] nesne sınıflandırmasında kullanılmak üzere yeni bir kovaryans tanımlayıcısı sunmuşlardır. Yan ve diğerleri [14] derin öğrenmeye dayanan zeki bir nesne tanıma çalışması yapmışlardır. Sujana ve diğerleri [15] gerçek zamanlı çalışan ve derin kıvrımlı sinir ağları kullanan bir nesne tanımlama çalışması yapmışlardır. Bychkov ve diğerleri [16] yaptıkları çalışmada kullanıcı bilgisini kullanarak raster görüntülerdeki nesneleri saptamışlardır. Hayat ve diğerleri [17] nesne tanıma için kıvrımlı sinir ağını kullanan bir derin öğrenme çalışması sunmuşlardır. Sonoda ve Kimoto [18] yer radar görüntülerindeki nesneleri saptayan bir çalışma yapmışlardır. Ren ve diğerleri [19] nesne tanıma ve kişiyi yeniden tanımlama için tek tip ve değişken bir derin öğrenme yöntemi sunmuşlardır. Seo ve Park [20] düşük çözünürlüklü görüntülerdeki

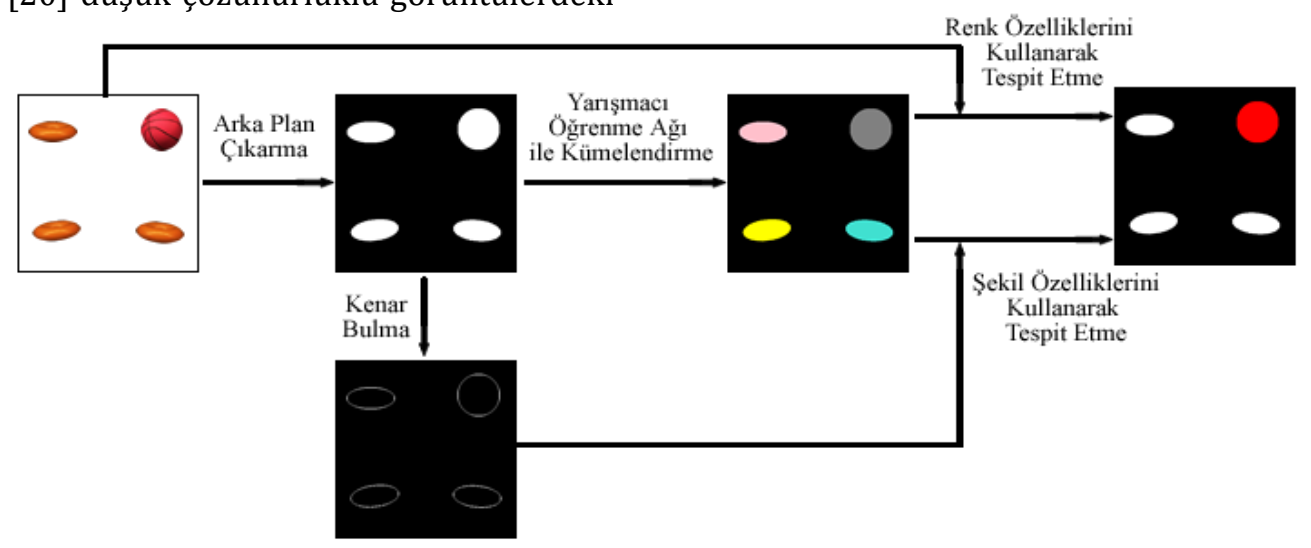

Şekil 1.Yöntemlerin uygulanma adımları

\section{Farklı Nesneyi Tespit Etme}

\subsection{Yarışmacı Öğrenme Ağı ile Nesneleri Belirleme}

Eğiticisiz öğrenmeye dayanan yarıșmacı öğrenme ağl kümeleme problemleri için kullanışlı bir ağdır. Yarışmacı öğrenme ağında çıkış birimlerinden sadece biri kazanır ve ağırlıkları güncellenir [24,25]. Bu çalışmada görüntü üzerindeki nesneleri belirlemek için yarışmacı öğrenme ağı kullanılmıştır. Şekil 2'de kullanılan 2 girișli ve 6 çıkışlı yarışmacı öğrenme ağı

Kullanılan yarışmacı öğrenme ağına giriş değerleri olarak arka planı çıkarılan görüntüdeki piksellerin gösterilmektedir. nesneleri tanıyan, derin işbirliğine dayalı öğrenme yöntemini kullanan bir çalışma yapmıșlardır. Divya [21] havadan çekilmiş görüntüler üzerindeki benzer Çalışmasında Gauss karışım modelini kullanmıştır. Liu ve diğerleri [22] uydu görüntülerindeki nesneleri ayırt etmek için geliştirilen evrişimli sinir ağı temelli bir çalışma sunmuşlardır. Jalal ve diğerleri [23] bir görüntü üzerindeki nesneleri ve sahneyi tanımlayan bir çalışma yapmışlardır.

$\mathrm{Bu}$ çalışmada, bir görüntü üzerindeki nesnelerden farklı olanı, renk ve şekil özelliklerini kullanarak tespit eden iki farklı yöntem sunulmaktadır. İlk olarak, arka planı çıkartılan görüntü üzerindeki nesneler yarışmacı öğrenme ağı ile kümelendirilerek belirlenmişlerdir. Görüntülerin arka planları tek renk olduğu için arka plan çıkarma işlemi basit bir algoritma ile gerçekleştirilmiştir. Sonra eğer renk özellikleri kullanılacaksa orijinal resimdeki nesnelerin renk değerleri ve kümelendirme işleminin sonuçları kullanılarak farklı nesne tespit edilmiştir. Şekil özellikleri kullanılacak ise de arka planı çıkarılmış görüntüye Sobel operatörü uygulanarak elde edilen kenarların tespit edildiği görüntü ve kümelendirme işleminin sonuçları kullanılarak farklı nesne tespit edilmiştir. Şekil 1'de iki yöntemin de uygulanma adımları gösterilmektedir. hedefleri tespit eden bir çalışma yapmıştır.

yatay ve dikeydeki konumları verilmiştir bu yüzden 2 girişlidir. Maksimum 6 nesne içeren görüntüler kullanıldığı içinde 6 çıkışlıdır. Görüntü üzerinde ne kadar nesne varsa o kadar sayıda farklı çıkış aktif olmaktadır. Böylece görüntü üzerindeki nesne sayısı da belirlenmektedir. Ăgdaki ağırlıklar nesnelerin görüntü üzerindeki merkez noktalarını temsil etmektedir. İlk değer olarak 6 farklı merkez noktası rastgele atanır. Her bir pikselin merkez noktalarına olan Öklid uzaklıkları hesaplanır. Piksel hangi merkez noktasına daha yakınsa ilgili çıkış kazanmış olur ve ağırlıkları yani merkez noktaları güncellenir. Güncellenme işlemi için kullanılan denklem Eşt. 1'de verilmiştir. 


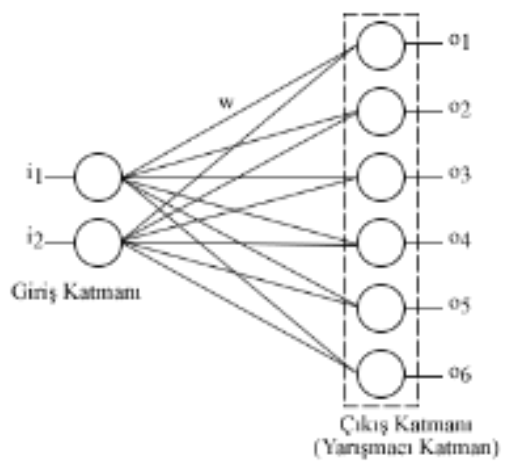

Şekil 2.2 girișli ve 6 çıkışlı yarışmacı öğrenme ağı

$w_{\text {io }}(t+1)=w_{\text {io }}(t)+\eta\left(i-w_{\text {io }}(t)\right)$

Eşt. 1'deki Wio(t+1) yeni ağırlık değerini, wio $(t)$ eski ağırlık değerini, i giriş değerini ve $\eta$ ağırlık azaltma oranını temsil etmektedir. Bu çalışmada ağırlık azaltma oranı olarak 0.5 değeri kullanılmıştır. Bu kümelendirme işleminin sonunda görüntü üzerinde kaç adet nesne olduğu, bu nesnelerin merkez noktası ve hangi pikselin hangi nesneye ait olduğu belirlenmektedir.

\subsection{Renk Özelliklerini Kullanarak Farklı Nesneyi Tespit Etme}

$\mathrm{Bu}$ yöntemde görüntü üzerinde belirlenen nesnelerin orijinal KYM (kırmızı-yeşil-mavi) renk değerleri kullanılarak farklı nesne tespit edilmiștir. Her bir nesne için Eşt. 2'deki denklem uygulanmıştır. Eşt. 2'deki $T_{n}$ ilgili nesnenin toplam piksel sayısını ve $p_{k} p_{y}$ $\mathrm{p}_{\mathrm{m}}$ sirasıyla her bir pikselin KYM renk değerlerini temsil etmektedir.

$\mathrm{O}_{\mathrm{kym}}=\frac{\sum_{\mathrm{p}=0}^{\mathrm{T}_{\mathrm{n}}}\left(\mathrm{p}_{\mathrm{k}}+\mathrm{p}_{\mathrm{y}}+\mathrm{p}_{\mathrm{m}}\right)}{\mathrm{T}_{\mathrm{n}}}$

Eşt. 2 ile her bir nesne için ortalama bir renk değeri hesaplanmıştır. Ortalama renk değeri diğerlerininkinden değişik olan nesne farklı kabul edilmiştir.

\section{3. Şekil Özelliklerini Kullanarak Farklı Nesneyi Tespit Etme}

$\mathrm{Bu}$ yöntemde görüntü üzerinde belirlenen nesnelerin şekilsel özellikleri kullanılarak farklı nesne tespit edilmiştir. Arka planı çıkarılmış görüntüye Sobel operatörü uygulanmış ve nesnelerin kenarları belirlenmiştir. Kenarların tespit edildiği bu görüntü üzerinde [26]'da sunulan geometrik özellikleri çlkarmak için kullanılan ilkel elemanlara benzer üç farklı temel şekil aranmıştır. Bu temel şekiller Şekil 3'de gösterilmektedir.
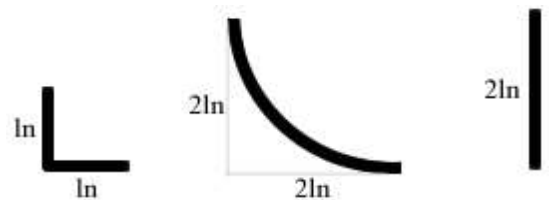

Şekil 3.Üç temel șekil

Temel şekillerin kalınlıkları 3 piksel olarak kabul edilmiştir. Uzunlukları ise Eşt. 3'deki denklem ile hesaplanmaktadır. Eşitlikteki $\mathrm{T}_{\mathrm{p}}$ bütün nesnelerin toplam piksel sayısını ve $\alpha$ nesnelerin sayısını temsil etmektedir. Eşt. 3 ile görüntü üzerindeki nesnelerin boyutları ile orantılı temel şekillerin oluşturulması amaçlanmıştır.

$\ln =\frac{\sqrt{\mathrm{T}_{\mathrm{p}} / \alpha}}{4}$

Üç temel şekil sırasıyla 8 farklı yönde döndürülerek görüntü üzerinde aranmıştır. Tespit edildiklerinde ilgili nesnenin şekil sayısı bir artırılmıştır. Böylece her bir nesne için üç adet temel șekil sayısı ortaya çıkmıştır. Her bir temel şekil için bu sayıların ortalama değerleri hesaplanmıștır. Eșt. 4, Eşt. 5 ve Eşt. 6'daki denklemler kullanılarak bu değerlerin aralarındaki fark hesaplanmıştır. Eşitliklerdeki o ortalama değeri, c nesnenin temel şekil sayısını ve $\delta$ aradaki mutlak farkı temsil etmektedir. Üç adet temel şekil olduğu için o ve $\delta$ üç farklı değer almaktadır. c değeri ise $\alpha$ kadar yani nesne sayısı kadar değer almaktadır.

$\delta_{1}=\left|c_{j}-o_{1}\right|$

$\delta_{2}=\left|c_{j}-o_{2}\right|$

$\delta_{3}=\left|c_{j}-o_{3}\right|$

Bütün nesneler arasında mutlak farkı en fazla olan değer aykırı değer olarak belirlenmiștir ve en fazla aykırı değere sahip olan nesne farklı olarak kabul edilmiştir.

\section{Deneysel Sonuçlar}

C\# dilinde bir program yazılarak önerilen yöntemler uygulanmış ve deneysel sonuçlar elde edilmiştir. Deneysel çalışmalar için [27]'de sunulan kütüphanedeki nesne görüntülerinden 80 tanesi kullanılmıştır. $\mathrm{Bu}$ nesne görüntüleri Şekil 4'de gösterilmektedir. Şekilde de görüldügü gibi bu nesneler ikişerli gruplara ayrılmıştır. Gruplardaki nesneler kullanilarak, her birinden 40'ar tane olmak üzere 3, 4, 5 ve 6 adet nesnenin olduğu toplam 160 tane görüntü oluşturulmuştur. Bu görüntülerde ilgili gruptaki nesnelerden birinden bir adet, diğerinden ise daha fazla sayıda bulunmaktadır yani her görüntüde bir tane farklı nesne yer almaktadır.

Davies-Bouldin indeksi [28] kümeleme algoritmalarını değerlendirmek için kullanılan bir yöntemdir. Oluşturulan kümeler ne kadar homojen ve birbirlerinden uzaksa o kadar düșük bir DaviesBouldin indeksine sahip olurlar. Bu çalışmada yarışmacı öğrenme ağının kümelendirme performansını ölçmek için kullanılmıștır. Eşt. 7, Eşt. 8 ve Eșt. 9'daki denklemler kullanılarak hesaplanmıştır. Eşitliklerdeki DB Davies-Bouldin indeksini, N küme 
sayısını, S ilgili kümedeki elemanların kümenin merkezine olan ortalama uzaklığını ve M ilgili kümelerin merkezlerinin arasındaki uzaklığı temsil etmektedir.

$$
\begin{aligned}
& R_{i, j}=\frac{S_{i}+S_{j}}{M_{i, j}} \\
& D_{i}=\max _{j \neq i} R_{i, j} \\
& D B=\frac{1}{N} \sum_{i=1}^{N} D_{i}
\end{aligned}
$$

Şekil 5'de ki grafik de yarıșmacı öğrenme ağı kullanılarak elde edilen kümelerin Davies-Bouldin indeksleri gösterilmektedir. 3, 4, 5 ve 6 adet nesnenin olduğu toplam 160 tane görüntü üzerinde hesaplama yapılmıştır. Yataydaki değerler nesne çiftinin görüntü numarasını, dikeydeki değerler de DB değerlerini göstermektedir. Ortalama DB değerleri $3,4,5$ ve 6 nesneli görüntüler için sırayla $0.628,0.623,0.354$ ve 0.538 olarak hesaplanmıştır. Genel ortalama DB değeri de 0.535 olarak hesaplanmıştır.

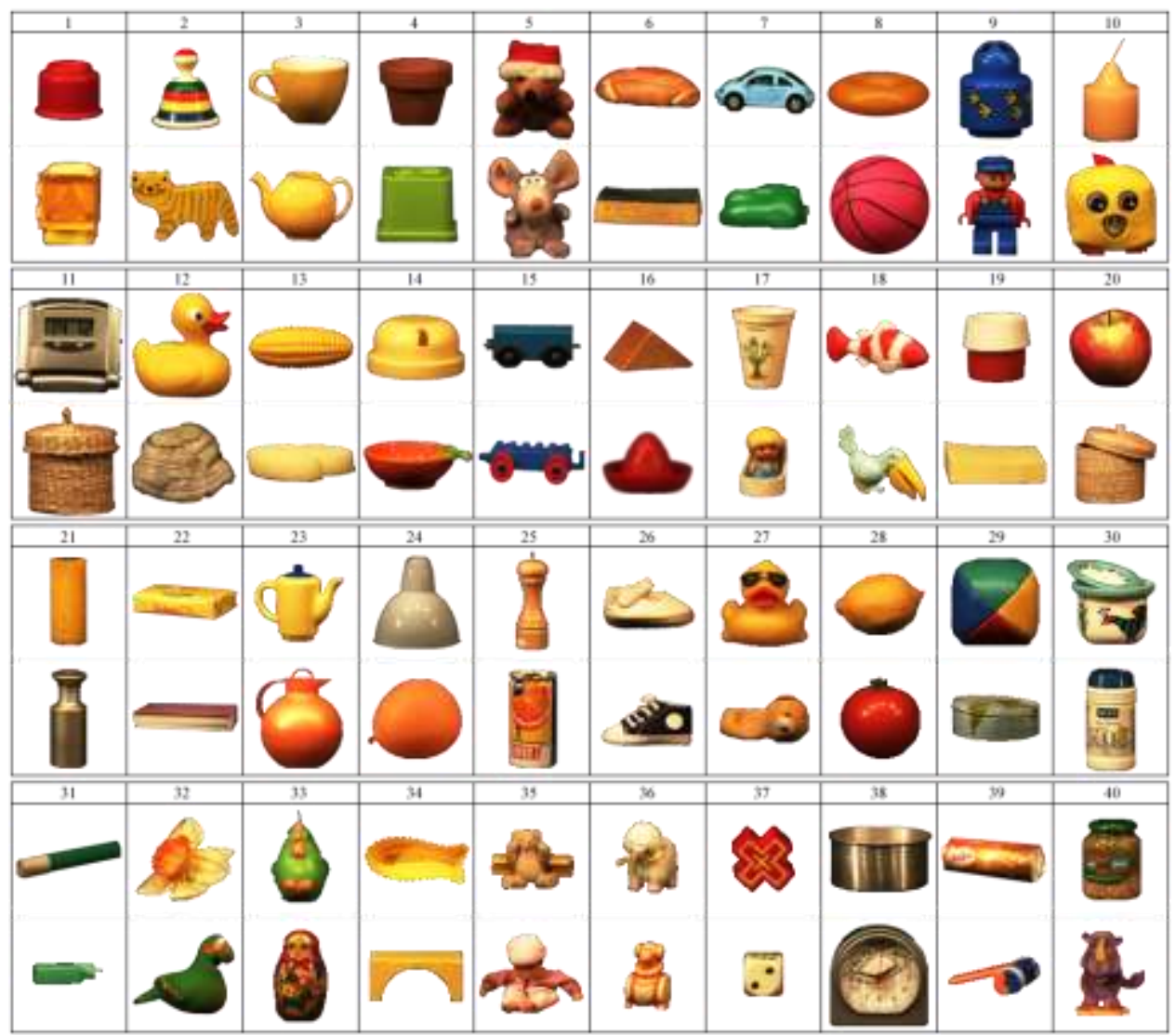

Şekil 4.Deneysel çalışmalarda kullanılan nesne görüntüleri [27]

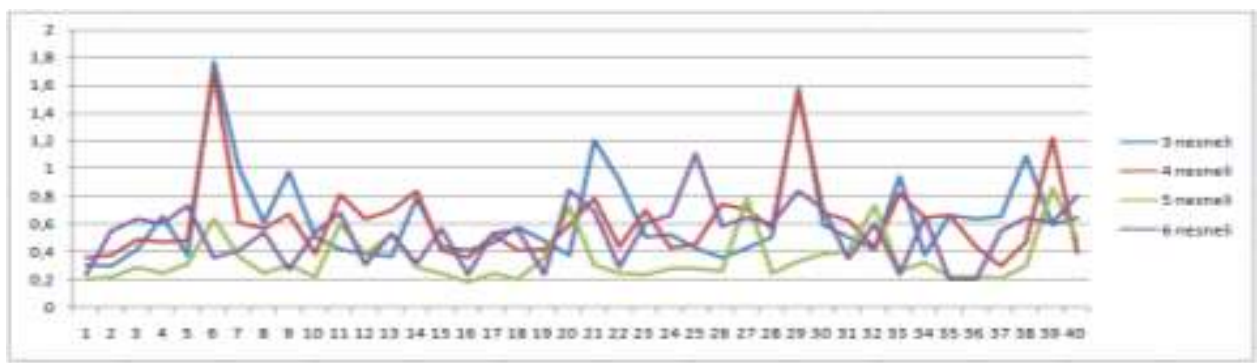

Şekil 5.Yarışmacı öğrenme ağı kullanılarak elde edilen kümelerin Davies-Bouldin indeksleri

Tablo 1 ve Tablo 2'de renk, Tablo 3 ve Tablo 4'de şekil özellikleri kullanılarak farklı nesnenin doğru bir şekilde tespit edilip edilmediği gösterilmektedir. İlk satırdaki değerler nesne çiftinin görüntü numarasını, ilk sütundaki değerlerde görüntü üzerindeki nesne sayısını belirtmektedir. Tablolardaki + değerler doğru tespiti, - değerlerde yanlıș tespiti belirtmektedir. Tablo 5'de her iki yöntem içinde elde edilen bașarı oranları gösterilmektedir.

Tablo 1. Renk özelliklerini kullanarak farklı nesne tespitin doğruluk değerleri (ilk 20 nesne çifti) 


\begin{tabular}{|c|c|c|c|c|c|c|c|c|c|c|c|c|c|c|c|c|c|c|c|c|}
\hline & 1 & 2 & 3 & 4 & 5 & 6 & 7 & 8 & 9 & 10 & 11 & 12 & 13 & 14 & 15 & 16 & 17 & 18 & 19 & 20 \\
\hline 3 & + & + & + & - & + & + & + & + & + & + & + & + & + & + & - & + & + & + & + & + \\
\hline 4 & + & + & + & - & + & + & + & + & + & + & + & + & + & + & - & + & + & + & + & + \\
\hline 5 & + & + & + & - & + & + & + & + & + & + & + & + & + & + & - & + & + & + & + & + \\
\hline 6 & + & + & + & - & + & + & + & + & + & + & + & + & + & + & - & + & + & + & + & + \\
\hline
\end{tabular}

Tablo 2. Renk özelliklerini kullanarak farklı nesne tespitin doğruluk değerleri (son 20 nesne çifti)

\begin{tabular}{|c|c|c|c|c|c|c|c|c|c|c|c|c|c|c|c|c|c|c|c|c|}
\hline & 21 & 22 & 23 & 24 & 25 & 26 & 27 & 28 & 29 & 30 & 31 & 32 & 33 & 34 & 35 & 36 & 37 & 38 & 39 & 40 \\
\hline 3 & + & + & + & + & + & + & - & + & + & - & + & + & + & + & + & + & + & + & + & + \\
\hline 4 & + & + & + & + & + & + & - & + & + & - & + & + & + & + & + & + & + & + & + & + \\
\hline 5 & + & + & + & + & + & + & - & + & + & - & + & + & + & + & + & + & + & + & + & + \\
\hline 6 & + & + & + & + & + & + & - & + & + & - & + & + & + & + & + & + & + & + & + & + \\
\hline
\end{tabular}

Tablo 3. Şekil özelliklerini kullanarak farklı nesne tespitin doğruluk değerleri (ilk 20 nesne çifti)

\begin{tabular}{|c|c|c|c|c|c|c|c|c|c|c|c|c|c|c|c|c|c|c|c|c|}
\hline & 1 & 2 & 3 & 4 & 5 & 6 & 7 & 8 & 9 & 10 & 11 & 12 & 13 & 14 & 15 & 16 & 17 & 18 & 19 & 20 \\
\hline 3 & + & + & + & + & - & + & - & - & + & + & + & + & + & + & + & + & + & - & + & + \\
\hline 4 & + & + & + & + & + & - & - & + & + & + & + & + & - & + & + & - & + & - & + & + \\
\hline 5 & + & + & + & + & + & - & - & + & + & - & - & + & - & + & + & - & + & - & + & + \\
\hline 6 & + & + & + & + & - & - & - & + & + & - & - & + & - & + & + & - & + & - & + & + \\
\hline
\end{tabular}

Tablo 4. Şekil özelliklerini kullanarak farklı nesne tespitin doğruluk değerleri (son 20 nesne çifti)

\begin{tabular}{|c|c|c|c|c|c|c|c|c|c|c|c|c|c|c|c|c|c|c|c|c|}
\hline & 21 & 22 & 23 & 24 & 25 & 26 & 27 & 28 & 29 & 30 & 31 & 32 & 33 & 34 & 35 & 36 & 37 & 38 & 39 & 40 \\
\hline 3 & + & + & + & + & + & + & + & + & + & + & - & - & - & + & + & + & + & + & + & - \\
\hline 4 & + & + & + & + & + & + & + & + & - & - & - & + & + & + & + & + & + & + & + & - \\
\hline 5 & + & - & + & + & + & + & - & + & + & + & + & + & + & + & - & + & + & + & + & - \\
\hline 6 & - & + & + & + & + & + & + & + & - & - & - & + & + & + & - & + & + & + & + & - \\
\hline
\end{tabular}

Tablo 5. Başarı oranları

\begin{tabular}{cccccc}
\hline Yöntem & 3 Nesneli & 4 Nesneli & 5 Nesneli & 6 Nesneli & Ortalama \\
\hline $\begin{array}{c}\text { Renk Özelliklerini } \\
\text { Kullanarak }\end{array}$ & $\% 90$ & $\% 90$ & $\% 90$ & $\% 90$ & $\% 90$ \\
\hline $\begin{array}{c}\text { Sekil Özelliklerini } \\
\text { Kullanarak }\end{array}$ & $\% 80$ & $\% 77.5$ & $\% 72.5$ & $\% 65$ & $\% 73.75$ \\
\hline
\end{tabular}

Deneysel sonuçlar incelendiğinde ortaya çıkan durumlar;

- Renk özelliklerini kullanan yöntem şekil özelliklerini kullanan yöntemden daha iyi sonuçlar elde etmiştir ancak renk özelliklerini kullanan yöntemin başarısız olduğu 4 ve 15 numaralı görüntülerde şekil özelliklerini kullanan yöntem başarılı olmuştur.

- Renk özelliklerini kullanan yöntem farklı nesne sayılarında hep aynı görüntülerde başarısız olurken şekil özelliklerini kullanan yöntemde farklılıklar gözlenmiştir.

- Renk özelliklerini kullanan yöntem farklı nesne sayılarında aynı başarı oranına sahipken şekil özelliklerini kullanan yöntemin başarı oranı nesne sayısı arttıkça azalmıştır.

- Her iki yöntemde de nesneler görüntü üzerine farklı yönlerde yerleştirilse de doğru sonuçlar elde edilmiştir.
- $\quad$ Renk özelliklerini kullanan yöntemde nesneler görüntü üzerine farklı boyutlarda yerleștirilse de doğru sonuçlar elde edilmiştir.

Önerilen yöntemler farklı nesneyi tespit ederken aslında benzer nesneleri de tespit etmiş oluyorlar çünkü farklı nesne haricindeki nesneler benzer nesnelerdir. Benzer nesneleri tespit eden literatürdeki diğer çalışmalar incelendiğinde, [5]'de sunulan yöntemin \%96.9 duyarlılık ve \%99.6 kesinlik oranına sahip olduğu görülmektedir. [21]'de sunulan yöntem üç farklı görüntü üzerinde test edilmiştir ve sadece bir görüntüdeki bir adet nesne tespit edilememiştir.

\section{Sonuç}

$\mathrm{Bu}$ çalışmada, bir görüntü üzerindeki nesnelerden farklı olanı, renk ve şekil özelliklerini kullanarak tespit eden iki farklı yöntem sunulmuştur. Renk özelliklerini kullanan yöntem ortalama \%90, şekil özelliklerini kullanan yöntem ise ortalama \%73.75 başarı elde etmiştir. İlk yöntemin başarı oranı daha yüksek olsa da 
iki yöntem arasından seçim yapılırken görüntüdeki nesnelerin özellikleri dikkate alınmalıdır. Sunulan yöntemler endüstride kırık yada kusurlu üretilen ürünün tespiti ve tarımda bozuk yada olgun meyvesebzenin belirlenmesi gibi çeşitli alanlarda kullanılabilecek uygulamalar için temel oluşturmaktadır. İlerleyen çalışmalarda bu uygulamalar geliştirilebilir.

\section{Kaynakça}

[1] Chen, Y., Zhu, L., Yuille, A., Zhang, H. 2009. Unsupervised Learning of Probabilistic Object Models (POMs) for Object Classification, Segmentation, and Recognition Using Knowledge Propagation. IEEE Transactions on Pattern Analysis and Machine Intelligence, 31(10), 17471761.

[2] Sahbi, H., Audibert, J., Keriven, R. 2011. ContextDependent Kernels for Object Classification. IEEE Transactions on Pattern Analysis and Machine Intelligence, 33(4), 699-708.

[3] Chen, J., Hu, C., Yuan, X., Feng, Z., Miao, H. 2013. An Identification and Classification Method for Circular Object Based on Rotating Image Template Matching. IEEE International Conference on Mechatronics and Automation, 47 Aug., Takamatsu, Japan, 1338- 1343.

[4] Kim, K., Kang, S., Kim, J., Lee, J., Kim, J., Kim, J. 2013. Multiple Objects Recognition for Industrial Robot Applications. 10th International Conference on Ubiquitous Robots and Ambient Intelligence, 30 Oct.-2 Nov., Jeju, Korea, 257-259.

[5] Higa, K., Iwamoto, K., Nomura, T. 2013. Multiple Object Identification Using Grid Voting of Object Center Estimated from Keypoint Matches. IEEE International Conference on Image Processing, 15-18 Sept., Melbourne, Australia, 2973-2977.

[6] Jang, H., Yang, H., Jeong, D., Lee, H. 2015. Object Classification using CNN for Video Traffic Detection System. 21st Korea-Japan Joint Workshop on Frontiers of Computer Vision, 2830 Jan., Mokpo, South Korea.

[7] Liang, C., Juang, C. 2015. Moving Object Classification Using a Combination of Static Appearance Features and Spatial and Temporal Entropy Values of Optical Flows. IEEE Transactions on Intelligent Transportation Systems, 16(6), 3453-3464.

[8] Oka, T., Morimoto, M. 2015. An Extraction and Recognition Method for Partially Hidden Objects. International Conference on Informatics, Electronics \& Vision, 15-18 June, Fukuoka, Japan.

[9] Shehnaz, M., Naveen, N. 2015. An Object Recognition Algorithm with Structure-Guided Saliency Detection and SVM Classifier. International Conference on Power, Instrumentation, Control and Computing, 9-11 Dec., Thrissur, India.

[10] Horiguchi, H., Ikeshiro, K., Imamura, H. 2016. Recognition for Objects by Relationship Between
Attributes. Third International Conference on Digital Information Processing, Data Mining, and Wireless Communications, 6-8 July, Moscow, Russia, 307-312.

[11] Dai, C. 2016. Online Surveillance Object Classification With Training Data Updating. International Conference on Audio, Language and Image Processing, 11-12 July, Shanghai, China, 733-737.

[12] Reddy, A. V. N., Phanikrishna, Ch. 2016. Contour Tracking Based Knowledge Extraction And Object Recognition Using Deep Learning Neural Networks. 2nd International Conference on Next Generation Computing Technologies, 14-16 Oct., Dehradun, India, 352-354.

[13] Zhang, H., Zhuang, B., Liu, Y. 2017. Object Classification Based on 3D Point Clouds Covariance Descriptor. IEEE International Conference on Computational Science and Engineering and IEEE International Conference on Embedded and Ubiquitous Computing, 21-24 July, Guangzhou, China, 234-237.

[14] Yan, L., Wang, Y., Song, T., Yin, Z. 2017. An Incremental Intelligent Object Recognition System Based on Deep Learning. Chinese Automation Congress, 20-22 0ct., Jinan, China, 7135-7138.

[15] Sujana, S. R., Abisheck, S. S., Ahmed, A. T., Chandran, K. R. S. 2017. Real Time Object Identification Using Deep Convolutional Neural Networks. International Conference on Communication and Signal Processing, 6-8 April, Chennai, India, 1801-1805.

[16] Bychkov, I. V., Rugnikov, G. M., Fedorov, R. K., Avramenko, Y.V. 2018. Object Identification on Raster Images by User Query. 3rd Russian-Pacific Conference on Computer Technology and Applications, 18-25 Aug., Vladivostok, Russia.

[17] Hayat, S., Kun, S., Tengtao, Z., Yu, Y., Tu, T., Du, Y. 2018. A Deep Learning Framework Using Convolutional Neural Network for Multi-class Object Recognition. IEEE 3rd International Conference on Image, Vision and Computing, 27 29 June, Chongqing, China, 194-198.

[18] Sonoda, J., Kimoto, T. 2018. Object Identification form GPR Images by Deep Learning. Asia-Pacific Microwave Conference, Kyoto, Japan, 1298-1300.

[19] Ren, L., Lu, J., Feng, J., Zhou, J. 2019. Uniform and Variational Deep Learning for RGB-D Object Recognition and Person Re-Identification. IEEE Transactions on Image Processing, 28(10), 4970 4983.

[20] Seo, J., Park, H. 2019. Object Recognition in Very Low Resolution Images Using Deep Collaborative Learning. IEEE Access, 7, 134071 - 134082.

[21] Divya, N. 2019. Image Specific Similar Target Detection in Aerial Images Using Gaussian Mixture Model. International Carnahan Conference on Security Technology, 1-3 Oct., Chennai, India. 
[22] Liu, K., Lee, P., Xu, G., Chang, B. 2020. SIFT Enhanced CNN Based Objects Recognition for Satellite Image. IEEE International Conference on Consumer Electronics, 28-30 Sept., Taoyuan, Taiwan.

[23] Jalal, A., Ahmed, A., Rafique, A. A., Kim, K. 2021. Scene Semantic Recognition Based on Modified Fuzzy C-Mean and Maximum Entropy Using Object-to-Object Relations. IEEE Access, 9, 27758 - 27772.

[24] Liu, J., Gao, M. 2008. Unsupervised Classification Algorithm for Intrusion Detection based on Competitive Learning Network. International Symposium on Information Science and Engieering, 20-22 Dec., Shanghai, China, 519-523.

[25] Theodoris, S., Koutroumbas, K. 2003. Pattern Recognition. 2nd edn, USA, Academic Press, chapter 15, 552-555.

[26] Kumar, G., Bhatia, P. K. 2014. A Detailed Review of Feature Extraction in Image Processing Systems. Fourth International Conference on Advanced Computing \& Communication Technologies, 8-9 Feb., Rohtak, India, 5-12.

[27] Geusebroek, J. M., Burghouts, G. J., Smeulders, A. W. M. 2005. The Amsterdam Library of Object Images. Int. J. Comput. Vision, 61(1), 103-112.

[28] Davies, D. L., Bouldin, D. W. 1979. A Cluster Separation Measure. IEEE Transactions on Pattern Analysis and Machine Intelligence, PAMI1(2), 224-227. 